\title{
Preparação de Argilas Organofílicas e Desenvolvimento de Nanocompósitos com Matrizes Poliméricas de Polietileno e Nylon6. Parte 1: Comportamento Mecânico
}

\author{
Edcleide M. Araújo, Tomás J. A. de Melo, Amanda D. de Oliveira, Homara L. D. Araújo, Kasselyne D. Araújo, Renata \\ Barbosa \\ Departamento de Engenharia de Materiais, UFCG
}

\begin{abstract}
Resumo: Argilas bentoníticas provenientes do Município de Boa Vista/PB foram utilizadas para a produção de argilas organofílicas. As argilas organofílicas foram obtidas a partir da síntese com quatro tipos de sais quaternários de amônio: cloreto de alquil dimetil benzil amônio (Dodigen), cloreto de estearil dimetil amônio (Praepagen), cloreto de cetil trimetil amônio (Genamin) e brometo de cetil trimetil amônio (Brometo). As argilas tratadas com os sais e a não tratada foram caracterizadas por difração de raios X (DRX) e espectroscopia de infravermelho por transformada de Fourier (FTIR). Em seguida, as argilas foram misturadas com matrizes poliméricas do tipo polietileno (PE) e nylon6 (PA6) por meio de técnicas convencionais de processamento. As misturas foram caracterizadas por DRX, microscopia eletrônica de varredura (MEV) e propriedades mecânicas. Os resultados obtidos por FTIR mostraram a presença dos grupos característicos dos sais na argila e o DRX confirmou a intercalação dos mesmos entre as camadas da argila. As propriedades mecânicas das misturas mostraram um aumento na rigidez em relação aos polímeros puros.
\end{abstract}

Palavras-chave: Argila bentonítica organofilica, nanocompósitos, polietileno, nylon6.

Preparation of Organophilic Clays and Development of Nanocomposites with Polyethylene and Nylon6 Polymer Matrices. Part 1: Mechanical Properties

\begin{abstract}
Bentonite clays from Boa Vista/PB were used to obtain organophilic clays. Organophilic clays were obtained with four types of quaternary salts of ammonium: asalkyldimethylbenzylammonium chloride (Dodigen), esthearildimethylammonium chloride (Praepagen), cethyltrimethylammonium chloride (Genamin) and cethyltrimethylammonium bromide (Bromide). The treated clays with salts and untreated clays were characterized by Xray diffraction (XRD) and Fourier transformed infrared spectroscopy (FTIR). Then, the clays were incorporated into polyethylene (PE) and Nylon6 (PA6) polymer matrices using conventional processing techniques. The mixtures were characterized by XRD, scanning electron microscopy (SEM) and mechanical properties. The results obtained by FTIR showed the presence of specific groups of the salts in the clay, while their intercalation among the clay layers was verified by XRD. As for the mechanical properties, the mixtures were more rigid than the pure polymers.
\end{abstract}

Keywords: Organophilic bentonite clay, nanocomposites, polyethylene, nylon6.

\section{Introdução}

Esmectita é o nome de um grupo de alumino-silicatos de sódio, magnésio, cálcio, ferro, potássio e lítio, que possui como principal argilomineral a montmorilonita. A rocha na qual as esmectitas são dominantes é chamada de bentonita. Os argilominerais deste grupo são constituídos por duas folhas de tetraedros de silicato com uma folha central de octaedros de alumínio, unidas entre si por oxigênio comuns às folhas ${ }^{[1]}$. Nesses silicatos com três camadas a capacidade para troca de íons varia tipicamente entre 70 a $80 \mathrm{meq} / 100 \mathrm{~g}^{[2]}$. As esmectitas sódicas, ou seja, con- tendo o sódio como cátion interlamelar preponderante são as de maior utilização industrial e estas podem ser obtidas, por meio de reação química a partir do carbonato de sódio, uma vez que na sua forma natural ela não é predominantemente sódica ${ }^{[3]}$. As argilas esmectíticas ou bentoníticas são caracterizadas por apresentar ou por poder ser desenvolvido nelas propriedades de uso tecnológico ${ }^{[4,5]}$. As argilas podem inchar na presença de água ou não. As argilas esmectíticas ou bentoníticas que não incham em presença de água são geralmente policatiônicas ou preponderantemente cálcicas. Aquelas que incham em água, possuem o sódio como cátion interlamelar preponderante e têm a pro-

Autor para correspondência: Edcleide M. Araújo, Departamento de Engenharia de Materiais, UFCG, Caixa Postal 10034, CEP: 58109-970, Campina Grande, PB. Email: edcleide@dema.ufcg.edu.br; 
priedade específica de aumentar até vinte vezes o volume da argila seca. Elas adsorvem água na forma de esferas de hidratação dos cátions $\mathrm{Na}^{+}$intercalados e são altamente hidrofílicas ${ }^{[4,6,7]}$.

As argilas organofílicas têm sido obtidas a partir da adição de sais quaternários de amônio (com pelo menos $12 \mathrm{ou}$ mais átomos de carbono em sua cadeia) em dispersões aquosas de argilas esmectíticas sódicas. Nessas dispersões aquosas as partículas elementares ou lamelas, devem encontrar-se (em maior ou menor grau) umas separadas das outras (e não empilhadas), facilitando a introdução dos compostos orgânicos, que irão torná-las organofílicas ${ }^{[7-10]}$. Dessa forma, os cátions orgânicos do sal substituem os cátions da argila sódica, passando-a de hidrofílica para organofílica ${ }^{[11]}$. Essa troca é importante não só para igualar a polaridade da superfície da argila com a polaridade do polímero, mas também para aumentar as distâncias entre as camadas (espaçamento basal). Na montmorilonita, ocorre aumento da distância entre as camadas de 0,98 para 1,2 a $2,5 \mathrm{~nm}$ - conforme o comprimento da cadeia do sal quaternário de amônio. A argila assim obtida não mais será solúvel em água e será compatível com matrizes poliméricas, desde que tenham sido escolhidos os íons de amônio orgânicos adequados ${ }^{[2,12]}$. Os nanocompósitos polímero/argila exibem em geral propriedades atraentes do ponto de vista óptico, elétrico e de barreira, além da redução de inflamabilidade das resinas em que são empregados. Nos nanocompósitos polímero/argila, a fase dispersa (argila) está presente sob a forma de lamelas de aproximadamente $10 \AA$ de espessura e vários mícrons de largura e comprimento, possuindo, portanto fator de forma (relação comprimento/ espessura) elevadíssimo. As cargas, dentro dos nanocompósitos estão dispersas e interagindo com o polímero em escala nanométrica ${ }^{[13]}$.

O objetivo desse trabalho é obter argilas organofílicas e com elas produzir nanocompósitos com matrizes poliméricas de polietileno (PE) e nylon6 (PA6). Para tornar as argilas organofílicas, serão testados quatro tipos diferentes de sais quaternários de amônio, para observação do desempenho deles nas propriedades dos nanocompósitos produzidos.

\section{Experimental}

Utilizou-se a argila bentonítica sódica BRASGEL PA, fornecida pela Indústria Bentonit União Nordeste (BUN), localizada em Campina Grande - PB. Para tornar as argilas mais compatíveis com o polímero, os íons de sódio foram trocados por íons de amônio. Essa troca foi realizada na presença de quatro sais quaternários de amônio distintos: o Dodigen (cloreto de alquil dimetil benzil amônio), o Praepagen (cloreto de estearil dimetil amônio), o Genamin (cloreto de cetil trimetil amônio), fornecidos pela Clariant São Paulo e o Brometo (brometo de cetil trimetil amônio), produzido pela VETEC - São Paulo/SP.

A preparação da argila organofílica tratada com os sais: Dodigen, Praepagen e Genamin é similar. Portanto, foram preparadas dispersões contendo $768 \mathrm{ml}$ de água destilada e
$32 \mathrm{~g}$ de argila. A argila foi adicionada aos poucos com agitação mecânica concomitante e mantida por 20 minutos. Em seguida, foi adicionada uma solução contendo água destilada e o sal quaternário de amônio. A agitação foi mantida por mais 20 minutos. Em seguida, os recipientes foram fechados e mantidos à temperatura ambiente por 24 horas. Após esse tempo, o material obtido foi filtrado para ser retirado o excesso de sal. A lavagem foi feita com aproximadamente 2000ml de água destilada empregando Funil de Buchner com kitassato, acoplado a uma bomba de vácuo. Os aglomerados obtidos foram secados em estufa a $60^{\circ} \mathrm{C} \pm 5^{\circ} \mathrm{C}$, por um período de 48 horas. Finalmente, os aglomerados já secos foram desagregados e passados em peneira ABNT n ${ }^{\circ} 200$ (D = $0,074 \mathrm{~mm}$ ) para serem posteriormente caracterizados.

A preparação da argila organofílica tratada com o sal Brometo foi realizada a partir de dispersões contendo água destilada. Inicialmente, um becker com água destilada foi colocado em um aquecedor com temperatura controlada em $80^{\circ} \mathrm{C}$ $\pm 5^{\circ} \mathrm{C}$. Em seguida, a argila e o sal foram adicionados aos poucos e com agitação mecânica concomitante e contínua onde permaneceram por 20 minutos. Passado este tempo, seguiu-se o mesmo procedimento de filtração, desaglomeração e classificação granulométrica descrito anteriormente.

\section{Caracterização das argilas}

\section{Espectroscopia de Infravermelho}

As análises de FTIR das bentonitas foram realizadas em um Espectrômetro de Infravermelho marca AVATAR TM 360 ESP Nicolet, com varredura de 4000 a $400 \mathrm{~cm}^{-1}$. As amostras foram preparadas na forma de pastilhas misturadas com $\mathrm{KBr}$.

\section{Difração de raios-X}

Foi utilizado um aparelho de difração de raios-X Siemens, modelo D5000, utilizando radiação K $\alpha$ do Fe (1,936 A), operando na faixa $2 \theta$ de 0 a 10 graus, para analisar o grau de intercalação e/ou exfoliação das argilas na presença dos sais. Essas medidas foram realizadas diretamente no pó das argilas.

\section{Preparação dos (nano)compósitos}

As argilas com tratamento (ACT) e as sem tratamento (AST), foram misturadas com o polietileno (PE) em concentrações de 3 e $5 \%$ em peso, em um misturador interno acoplado a um Reômetro de Torque System 90 da HaakeBlucher, operando a $190^{\circ} \mathrm{C}$ e 60rpm, por 7 minutos. As amostras foram granuladas em moinho de facas e moldadas por compressão, na forma de corpos de prova de tração (ASTM D638) em prensa hidráulica à temperatura de $200{ }^{\circ} \mathrm{C}$ sob pressão de 9 toneladas por 2 minutos, com pré-prensagem de 30 segundos.

Os compósitos com matriz de Nylon6 (PA6), na proporção de 3 e $6 \%$ em peso de argila, foram preparados em uma extrusora de rosca dupla acoplada a um Reômetro de Torque System 90 da Haake-Blucher, nas seguintes condições de mistura: $230^{\circ} \mathrm{C}$ a $60 \mathrm{rpm}$. Para essa matriz foi utilizada apenas a argila tratada com o sal Brometo. Antes da mistura ser 
realizada na extrusora, um "master" foi obtido em um misturador interno acoplado a um Reômetro de Torque System 90 da Haake-Blucher, na proporção de 50/50\% em peso (PA6/ argila), nas condições de $240{ }^{\circ} \mathrm{C}, 10 \mathrm{~min}$ e $60 \mathrm{rpm}$. Este foi posteriormente triturado em moinho de facas e incorporado na extrusora, junto ao nylon 6 , para efeito de dispersão da argila no polímero, já que a mesma se apresenta na forma de um pó fino o que dificulta bastante sua dispersão com os grânulos de polímero na extrusora. O material final obtido da extrusora foi granulado em moinho de facas e moldado em prensa hidráulica, a $230^{\circ} \mathrm{C}$, na forma de corpos de prova de tração (ASTM D638). Antes de cada etapa de processamento, os materiais contendo nylon foram secados em estufa a $80^{\circ} \mathrm{C}$ por 48 horas, para a retirada de umidade.

\section{Caracterização dos (nano)compósitos}

\section{Difração de raios-X}

Filmes de PE/argila foram obtidos por compressão, na temperatura de $200{ }^{\circ} \mathrm{C}$ e analisados em um aparelho de difração de raios-X Siemens, modelo D5000, utilizando radiação $\mathrm{K} \alpha$ do $\mathrm{Fe}$ $(1,936 \AA)$, operando na faixa $2 \theta$ de 2 a 10 graus. Para as amostras de PA6, foram analisados os corpos de prova de PA6/argila,
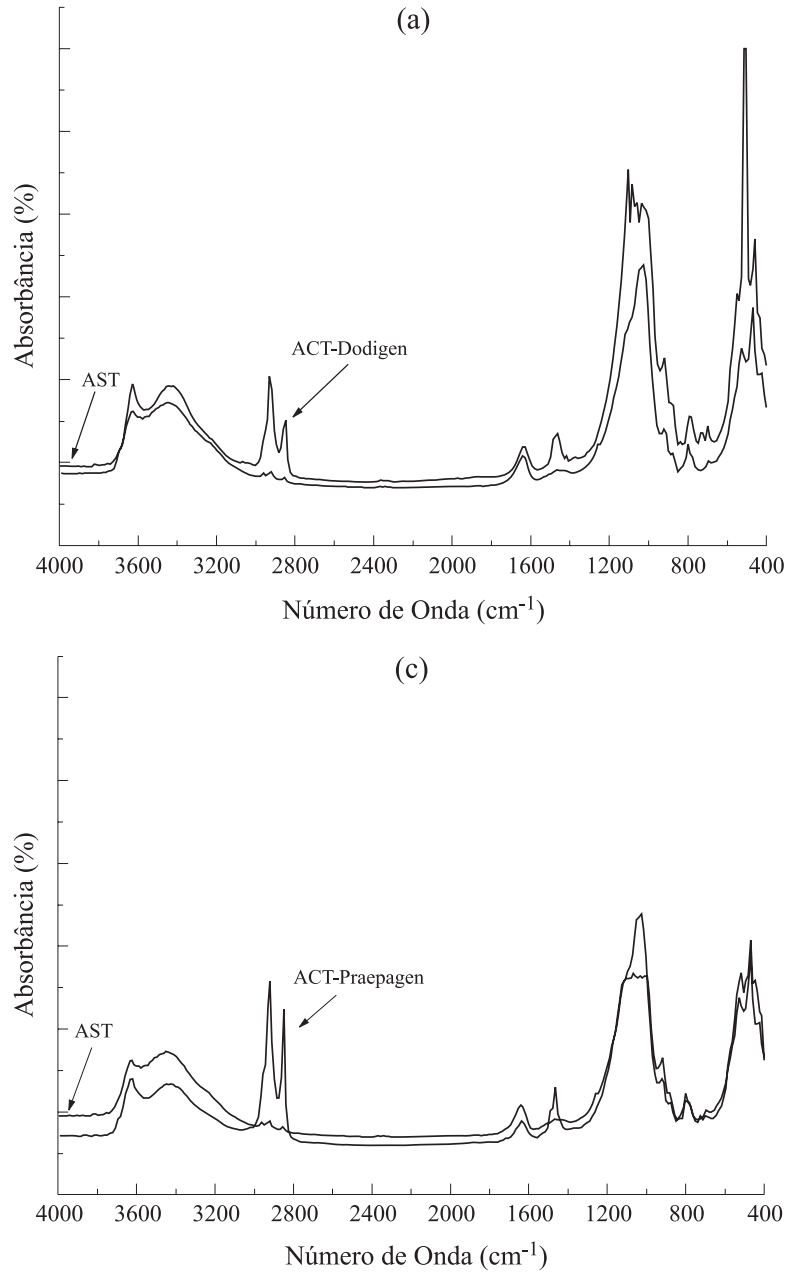

por difração de Raios-X, utilizando um aparelho Shimadzu XRD 6000, com radiação $\mathrm{K} \alpha$ do $\mathrm{Cu}(1,5418 \AA)$ (40Kv/30mA).

\section{Propriedades mecânicas}

Para o ensaio de tração, foi utilizada uma máquina universal de ensaios Lloyd Instruments $10 \mathrm{KN}$, operando a uma velocidade de deformação de $50 \mathrm{~mm} / \mathrm{min}$ para obtenção do módulo de elasticidade, resistência no escoamento e alongamento na ruptura, conforme norma ASTM D638. Foram ensaiados aproximadamente 5 (cinco) corpos de prova de cada composição.

\section{Microscopia eletrônica de varredura}

A análise morfológica foi realizada em um Microscópio Eletrônico de Varredura (MEV), marca Shimadzu, modelo SSX 550 SUPER SCAN. Foram analisadas as superfícies de fratura das amostras. Estas foram recobertas com ouro usando um IC-50 ION COATER, marca Shimadzu.

\section{Resultados e Discussão}

\section{Caracterização das argilas}

A Figura 1 apresenta os espectros na região do infravermelho da argila sem tratamento e tratada com os sais
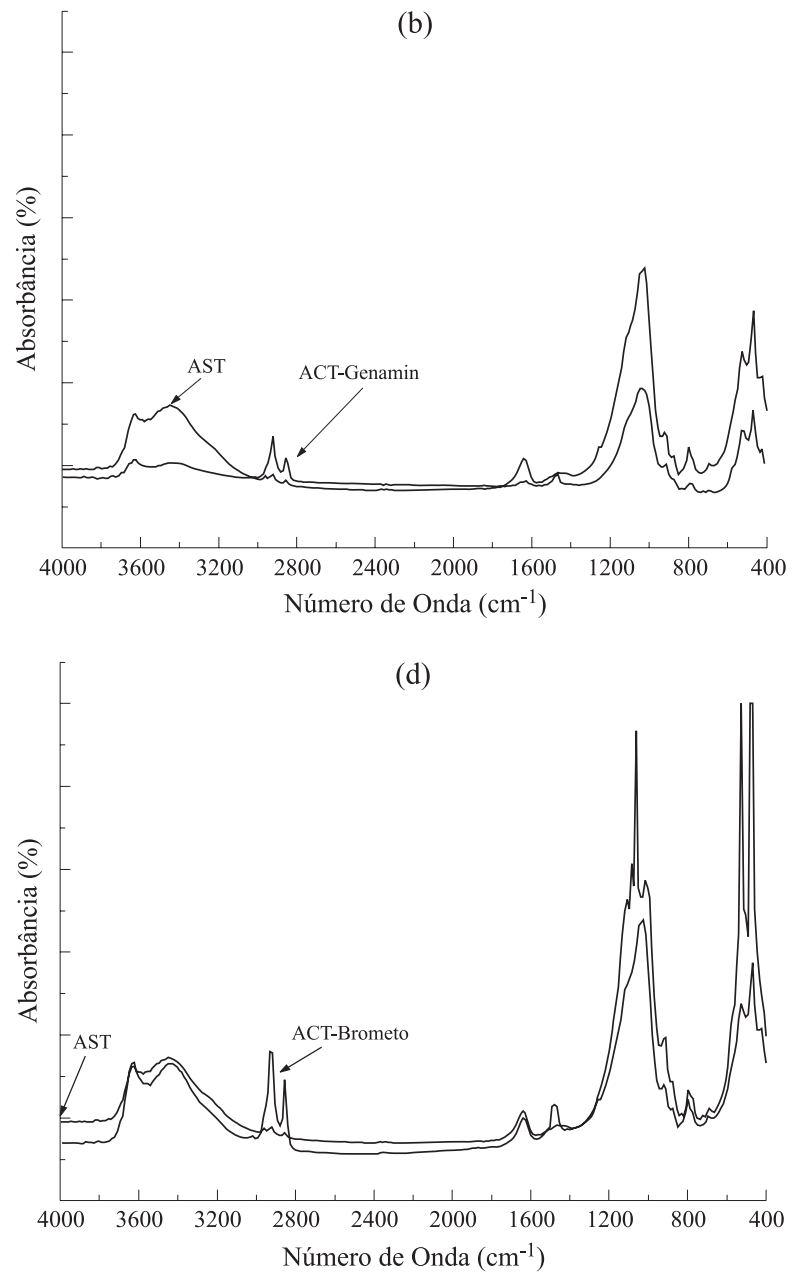

Figura 1. Espectros de Infravermelho da amostra natural e após tratamento de organofilização com os sais quaternários de amônio: (a) Dodigen, (b) Genamin, (c) Praepagen e (d) Brometo. 
quaternários de amônio Dodigen, Genamin, Praepagen e Brometo. Observando o espectro de infravermelho para a argila sem tratamento, verifica-se um pico em $3632 \mathrm{~cm}^{-1}$ referente à freqüência de vibração dos grupos $\mathrm{OH}$ da argila bentonítica. $\mathrm{O}$ pico presente a $3435 \mathrm{~cm}^{-1}$ corresponde às vibrações de $\mathrm{H}_{2} \mathrm{O}$ e o pico complexo a $1048 \mathrm{~cm}^{-1}$ está relacionado com as vibrações de grupos Si-O. A Figura compara os espectros da argila tratada com os da não tratada. Verifica-se que os picos característicos das camadas octaédricas são freqüentes nas faixas $920 \mathrm{~cm}^{-1}, 800 \mathrm{~cm}^{-1}$, e $525 \mathrm{~cm}^{-1} \mathrm{e}$ estão presentes tanto na argila tratada quanto na não tratada. Observam-se novas bandas na faixa de aproximadamente $3629 \mathrm{~cm}^{-1}$, que indicam a presença de vibrações do grupo $\mathrm{NH}$; bandas na faixa de $3001 \mathrm{~cm}^{-1}$ correspondentes a vibrações de estiramento assimétricos do grupo $\mathrm{CH}_{3}$; o par de bandas na faixa de 2846 e $2918 \mathrm{~cm}^{-1}$ é respectivamente as vibrações de estiramento simétricas e assimétricas do grupo $\mathrm{CH}_{2}$ e a banda na faixa de $1459 \mathrm{~cm}^{-1}$ indica vibração de flexão do grupo $\mathrm{CH}_{2}{ }^{[12,14]}$. A presença das bandas de absorção devido aos grupos $\mathrm{NH}, \mathrm{CH}_{3}$ e $\mathrm{CH}_{2}$ nos espectros de infravermelho das argilas bentoníticas tratadas, evidencia a presença do cátion quaternário de amônio nos espaços interlamelares da argila.

Os resultados de DRX da argila Brasgel PA sem tratamento e tratada com os sais Dodigen, Genamin, Praepagen e Brometo estão apresentados na Figura 2. Os picos característicos correspondem ao plano $\mathrm{d}_{001}$ das argilas. O pico característico para o plano (001) da argila não tratada aparece em aproximadamente $8,4^{\circ}$ e corresponde ao espaçamento basal $\left(\mathrm{d}_{001}\right)$ de $14,47 \AA$ A. Após a introdução dos sais, os picos de difração mudam e mostram um aumento do espaçamento basal de acordo com o tipo de sal, ou seja, $22,01 \AA$ para a bentonita tratada com o Dodigen; $21,82 \AA$ para a bentonita tratada com o sal Genamin; $35,16 \AA$ para a bentonita tratada com o sal Praepagen e $39,1 \AA$ para a bentonita tratada com sal Brometo. A partir dos resultados de DRX não se pôde fazer uma correlação entre a estrutura química do sal e o aumento da distância interplanar basal da argila, pois quando se comparam às estruturas moleculares dos sais Genamin e Brometo, ambas são semelhantes diferencian-

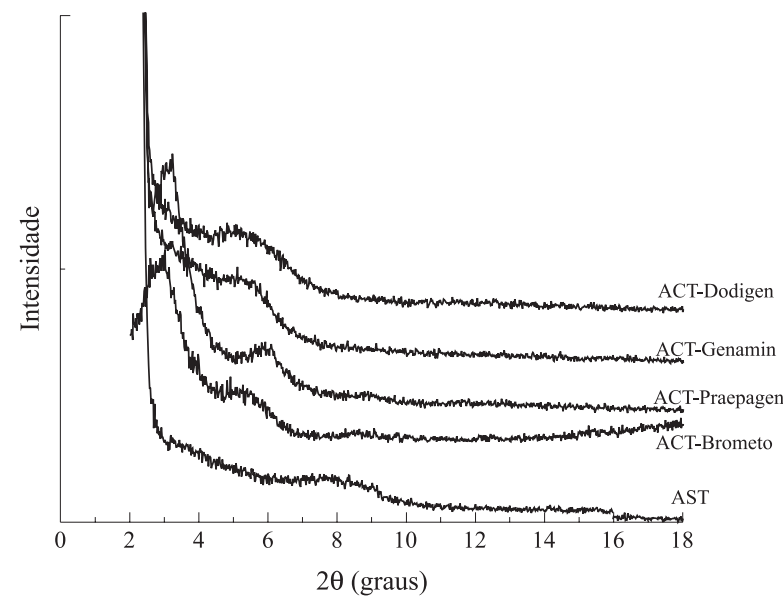

Figura 2. Difratogramas da argila sem tratamento e tratada com os sais Dodigen, Genamin, Praepagen e Brometo
Tabela 1. Distância Interplanar Basal da argila sem tratamento e tratada com os sais quaternários de amônio

\begin{tabular}{lc}
\hline \multicolumn{1}{c}{ Amostra } & Espaçamento basal (̊̊) \\
\hline Argila sem tratamento & 14,5 \\
Argila tratada com dodigen & 22,0 \\
Argila tratada com genamin & 21,8 \\
Argila tratada com praepagen & 35,2 \\
Argila tratada com brometo & 39,1 \\
\hline
\end{tabular}

do-se apenas no ânion (um tem cloro e o outro tem bromo, respectivamente) e, no entanto, as distâncias interplanar basal foram bem diferentes sendo 21,82 Å para a argila com Genamin e $39,1 \AA$ para a argila com Brometo. Os resultados indicam uma intercalação dos íons dos sais quaternários de amônio dentro das camadas de silicato com conseqüente expansão do espaçamento basal $\mathrm{d}_{001}$, de acordo com a literatura ${ }^{[15,16]}$. Dessa forma, a compatibilidade da argila com o polímero é favorecida durante o processamento. Os sais Brometo e Praepagen foram mais eficientes na organofilização do que o Dodigen e o Genamin como indicado pelos maiores valores da distância interplanar basal. Caso interessante também é observado para a argila na presença do sal Praepagen, onde um segundo pico aparece em $2 \theta=5,98^{\circ}$, correspondendo à distância $18,56 \AA$. Esse pico pode ser atribuído ao $\mathrm{d}_{002}$ que é um plano paralelo ao $\mathrm{d}_{001}=35,16 \AA$, conforme observado em outro trabalho ${ }^{[15]}$. A Tabela 1 apresenta os valores da distância interplanar basal para a argila tratada com os quatro sais quaternários de amônio.

\section{Caracterização dos (nano)compósitos de PE}

A Figura 3 mostra os padrões de difração de raios-X para as misturas de $\mathrm{PE}$ com 5\% de Argila. Comparando-se os sistemas PE/AST e PE/ACT-Praepagen, podem ser observados dois picos de difração para o sistema com o sal Praepagen. Para as misturas com os sais Dodigen e Genamin, são observados picos

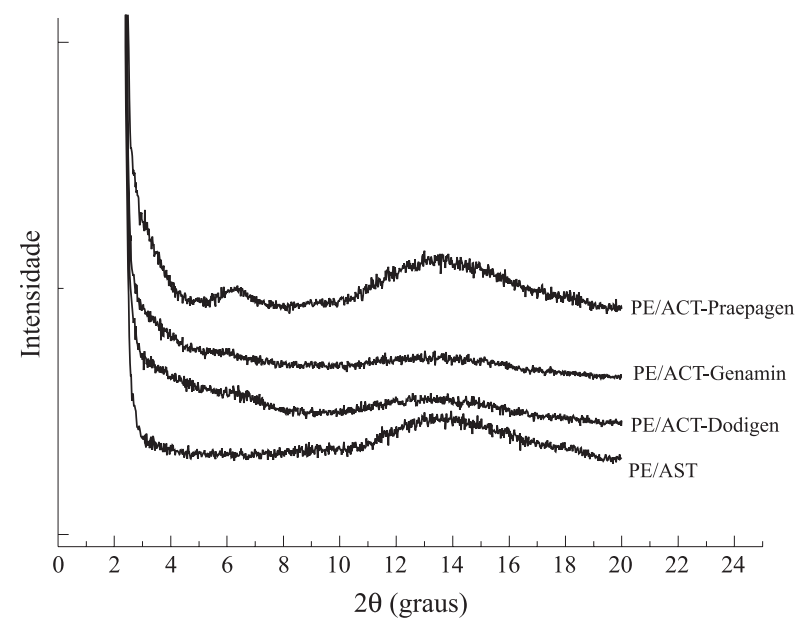

Figura 3. Padrões de difração de raios-X de Polietileno com 5\% de Argila: PE/AST (Argila sem tratamento); PE/ACT-Dodigen (Argila tratada com Dodigen); PE/ACT-Genamin (Argila tratada com genamin) e PE/ACTPraepagen (Argila tratada com Praepagen). 
mais alargados e menos intensos na mesma faixa do ângulo de reflexão (20). Esse comportamento nos sistemas PE/ACTDodigen e PE/ACT-Genamin pode indicar exfoliação ${ }^{[16]}$. Comportamento semelhante foi observado para os padrões de difração das amostras de PE com 3\% em peso de argila.

As Tabelas 2 e 3 mostram os resultados dos ensaios mecânicos de tração para o polietileno puro e suas misturas com 5 e $3 \%$ em peso de argila bentonítica sem tratamento e tratada com os sais. Observa-se que o teor de carga exerce efeito considerável nas propriedades mecânicas dos materiais estudados. Entretanto, os tipos de tratamentos utilizados com diferentes sais parecem não influenciar as propriedades mecânicas. Em todos os sistemas investigados, observam-se melhores propriedades mecânicas para baixos teores de carga (3\% em peso). Tanto a resistência à tração quanto o módulo de elasticidade tenderam a decrescer quando aumentamos o teor de carga. O sistema contendo polietileno com 3\% de argila sem tratamento mostrou aumento significante no módulo de elasticidade quando se compara com o mesmo sistema em concentrações de $5 \%$ em peso, ou seja, houve um aumento no módulo de elasticidade de $53 \%$. Em princípio, o aumento no teor de carga proporciona aglomeração o que reduz as propriedades mecânicas. Os valores de alongamento na ruptura dos sistemas $\mathrm{PE} /$ bentonita foram relativamente baixos quando comparados aos da matriz e cresceram com o aumento do teor de carga. Estes resultados são muito interessantes devido ao baixo teor de argila empregado e ao efeito

Tabela 2. Propriedades mecânicas do PE puro e dos sistemas PE com 5\% em peso de argila

\begin{tabular}{lccc}
\hline \multicolumn{1}{c}{ Material } & $\begin{array}{c}\text { Módulo de } \\
\text { Elasticidade } \\
(\mathbf{M P a})\end{array}$ & $\begin{array}{c}\text { Resistência } \\
\text { à Tração } \\
(\mathbf{M P a})\end{array}$ & $\begin{array}{c}\text { Alongamento } \\
\text { na ruptura } \\
(\mathbf{\%})\end{array}$ \\
\hline PE Puro & $741,7 \pm 15,1$ & $22,5 \pm 0,5$ & $11,1 \pm 0,7$ \\
PE+AST & $846,1 \pm 44,6$ & $21,6 \pm 0,4$ & $9,7 \pm 0,5$ \\
PE+ACT/Dod & $860,3 \pm 54,8$ & $19,5 \pm 0,9$ & $9,1 \pm 1,0$ \\
PE+ACT/Praep & $981,4 \pm 71,6$ & $20,8 \pm 0,6$ & $8,8 \pm 0,8$ \\
PE+ACT/Gen & $990,8 \pm 68,8$ & $21,0 \pm 1,3$ & $8,9 \pm 0,8$ \\
PE+ACT/Brom & $1103,3 \pm 46,2$ & $20,4 \pm 0,2$ & $8,2 \pm 0,4$ \\
\hline
\end{tabular}

Tabela 3. Propriedades mecânicas do PE puro e dos sistemas PE com 3\% em peso de argila

\begin{tabular}{lccc}
\hline \multicolumn{1}{c}{ Material } & $\begin{array}{c}\text { Módulo de } \\
\text { Elasticidade } \\
(\mathbf{M P a})\end{array}$ & $\begin{array}{c}\text { Resistência } \\
\text { à Tração } \\
(\mathbf{M P a})\end{array}$ & $\begin{array}{c}\text { Alongamento } \\
\text { na ruptura } \\
(\mathbf{\%})\end{array}$ \\
\hline PE Puro & $741,7 \pm 15,1$ & $22,5 \pm 0,5$ & $11,1 \pm 0,7$ \\
PE+AST & $1297,4 \pm 127,4$ & $22,8 \pm 1,6$ & $6,7 \pm 1,4$ \\
PE+ACT/Dod & $1153,1 \pm 123,5$ & $24,5 \pm 0,8$ & $7,8 \pm 0,5$ \\
PE+ACT/Praep & $1123,8 \pm 112,8$ & $22,2 \pm 4,7$ & $6,8 \pm 2,1$ \\
PE+ACT/Gen & $1179,5 \pm 116,1$ & $24,5 \pm 1,0$ & $7,8 \pm 0,8$ \\
PE+ACT/Brom & $1131,7 \pm 75,2$ & $23,5 \pm 1,0$ & $8,9 \pm 1,2$ \\
\hline
\end{tabular}

acentuado no aumento da rigidez nas propriedades mecânicas dos materiais.

A Figura 4 apresenta as fotomicrografias do polietileno (PE) puro e suas misturas PE/argila Brasgel (3\%) sem tratamento e tratada com o sal Genamin obtidas por obtidas por MEV. Na Figura 4(a), observa-se a superfície de fratura do PE puro mostrando o tipo de deformação e a presença de vazios. Essa deformação pode ser do tipo deformação plástica e/ou escoamento por cisalhamento. Na Figura 4(b) - PE/ AST, observam-se vazios na morfologia, o que indica que provavelmente a argila foi arrancada da matriz durante à solicitação ou esses vazios podem ser bolhas resultantes do tipo de moldagem. Na Figura 4(c) (PE/ACT-Genamin), aparece a argila no $\mathrm{PE}$ e de acordo com a análise por EDX, essa contem os elementos $\mathrm{C}, \mathrm{O}, \mathrm{Al}, \mathrm{Si}$ e Fe, confirmando a sua presença. A presença de vazios também é observada. A Figura 5 apresenta as superfícies de fratura das misturas para a com-

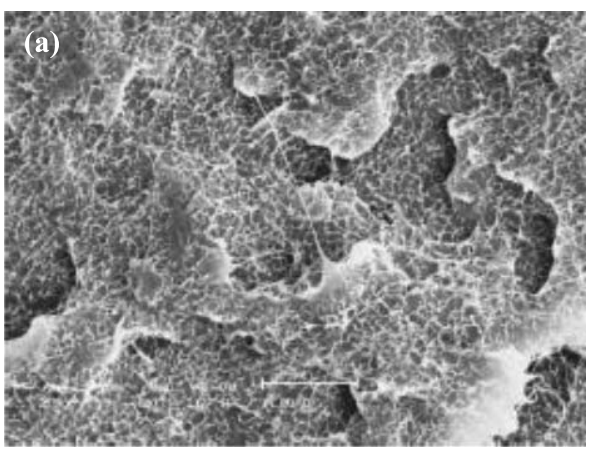

(800X)

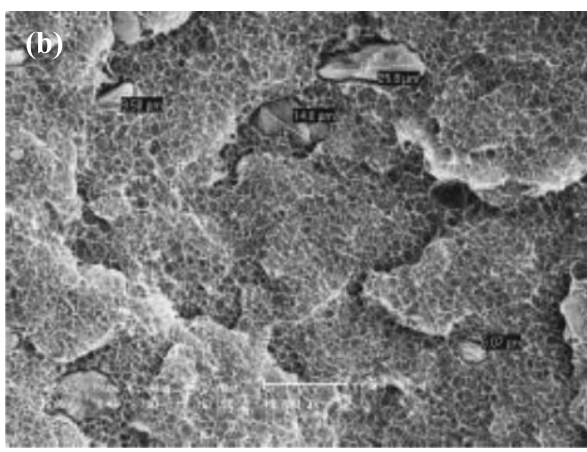

(700X)

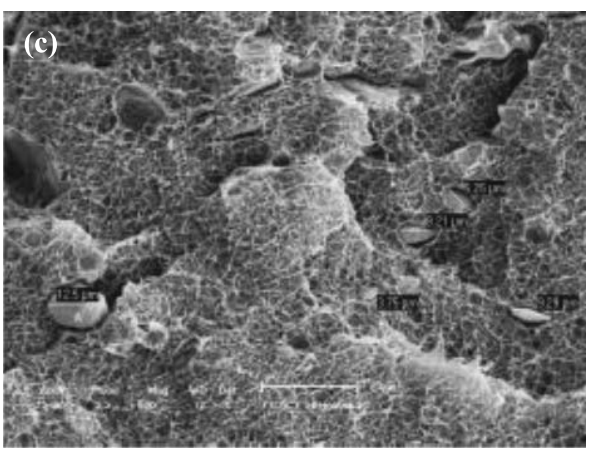

$(800 \mathrm{X})$

Figura 4. Fotomicrografias de MEV para (a) PE puro e PE com 3\% em peso de argila: (b) PE/argila Brasgel sem tratamento; (c) PE/argila Brasgel tratada com o sal Genamin. 


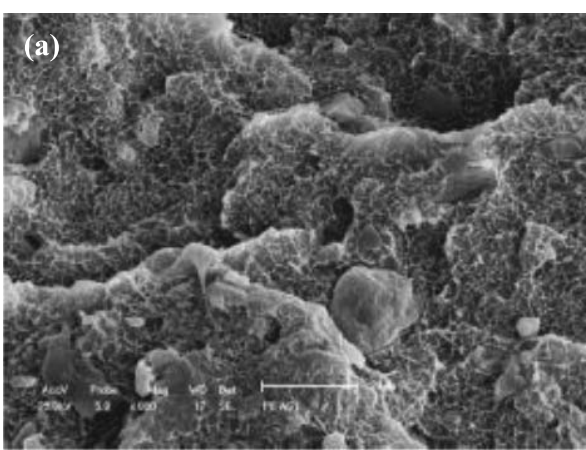

$(800 X)$

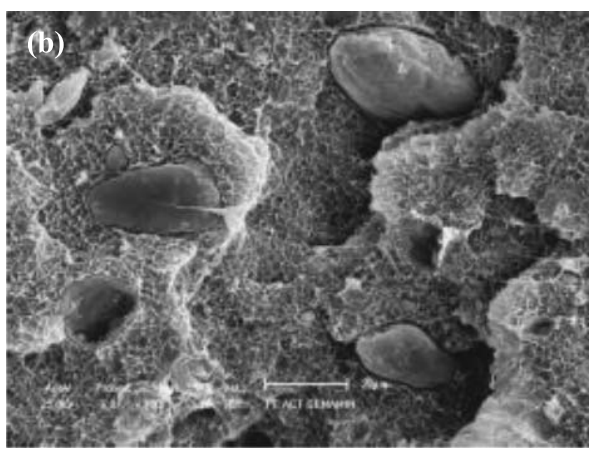

$(700 \mathrm{X})$

Figura 5. Fotomicrografias de MEV para amostras de PE com $5 \%$ em peso de argila: (a) PE/argila Brasgel sem tratamento; (b) PE/argila Brasgel tratada com o sal Genamin.

posição de 5\% em peso de argila. A Figura 5(a) mostra a superfície de fratura do PE/AST e a Figura 5(b) mostra a fotomicrografia do PE com argila na presença do sal Genamin. As superfícies de fratura apresentadas na Figura 5 aparentemente não diferem daquelas apresentadas na Figura 4. Para as duas composições, é interessante observar que a distribuição e a dispersão das partículas parecem ser semelhantes. $\mathrm{O}$ tamanho de partículas para a composição com $3 \%$ em peso de argila aparentemente é menor. O que confirma os melhores resultados de propriedades mecânicas obtidos, tais como o módulo e a resistência à tração.

\section{Caracterização dos (nano)compósitos de PA6}

A Figura 6 mostra os padrões de difração de raios-X para o sistema de PA6/argila e para o pó da argila tratada com o sal Brometo. Pode-se observar os picos de difração para a argila tratada com o sal brometo, indicando a intercalação dos íons desse sal dentro das camadas de silicato com conseqüente expansão do espaçamento basal (de 14,47 para 39,1 $)$ conforme comentado anteriormente. Para o PA6 puro e suas misturas com 3 e $6 \%$ de argila sem tratamento, não se observa pico no intervalo estudado. Para as misturas com 3 e $6 \%$ de argila organofílica em PA6, picos aparecem em torno de $2,5^{\circ}$ ou abaixo desse valor ou pode ser também background do equipamento. Além disso, pode-se também sugerir exfoliação da argila na matriz de PA6 com expansão do espaçamento basal, o que excede também a faixa de teste do aparelho, conforme discutido por GONG et al ${ }^{[16]}$. Todas essas suposições podem ser confirmadas por meio da técnica

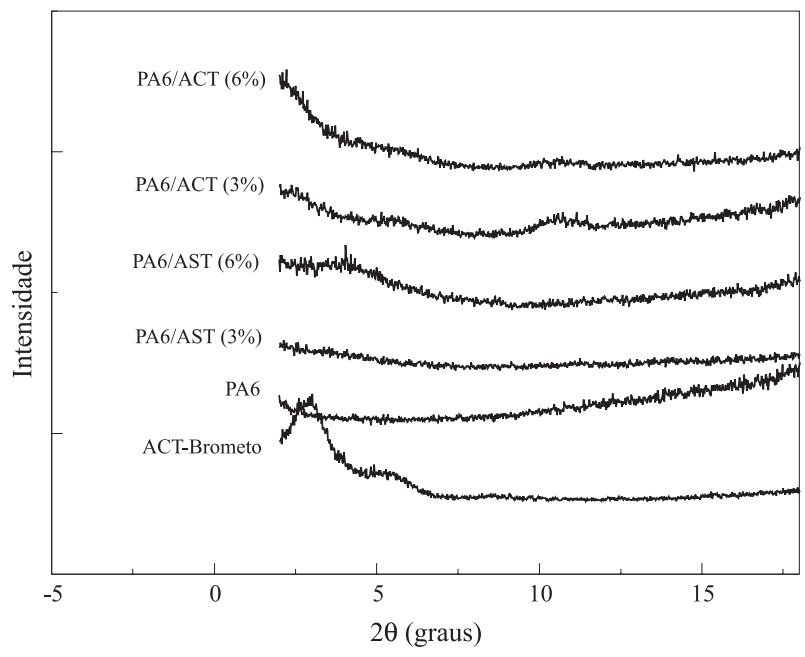

Figura 6. Padrões de difração de raios-X da argila tratada com brometo e das misturas de PA6/argila sem tratamento e PA6/argila com tratamento, para as composições de 3 e $6 \%$ de argila.

Tabela 4. Propriedades mecânicas da PA6 e dos sistemas PA6 com 3\% e $6 \%$ em peso de argila sem tratamento e tratada com o sal brometo

\begin{tabular}{lccc}
\hline \multicolumn{1}{c}{ Material } & $\begin{array}{c}\text { Módulo de } \\
\text { Elasticidade } \\
\text { (MPa) }\end{array}$ & $\begin{array}{c}\text { Resistência } \\
\text { à Tração } \\
(\mathbf{M P a})\end{array}$ & $\begin{array}{c}\text { Alongamento } \\
\text { na ruptura } \\
(\%)\end{array}$ \\
\hline Nylon6 & $1250,0 \pm 0,2$ & $47,7 \pm 2,4$ & $61,8 \pm 12,7$ \\
Nylon6/AST (3\%) & $1033,4 \pm 99,2$ & $41,9 \pm 2,4$ & $38,1 \pm 7,6$ \\
Nylon6/AST (6\%) & $1825,4 \pm 191$ & $36,1 \pm 1,6$ & $23,8 \pm 4,1$ \\
Nylon6/ACT (3\%) & $1424,7 \pm 80,2$ & $44,0 \pm 1,2$ & $16,1 \pm 1,3$ \\
Nylon6/ACT (6\%) & $1469,6 \pm 65,2$ & $40,4 \pm 1,9$ & $8,9 \pm 1,7$ \\
\hline
\end{tabular}

de MET. Esses estudos estão sendo realizados e serão apresentados posteriormente.

A Tabela 4 apresenta os resultados das propriedades mecânicas para a PA6 e suas misturas com argila sem tratamento e argila tratada com o sal brometo. Pode-se observar que a rigidez do material aumenta com o teor de argila. Para os compósitos de PA6/argila sem tratamento, observa-se um aumento no módulo de elasticidade e uma redução na resistência à tração. Um aumento é observado para o teor de 3\% em peso de argila tratada com o sal brometo e uma diminuição para o alongamento na ruptura. Tanto para o módulo quanto para o alongamento, o aumento do teor de argila tratada (3 para 6\%) parece afetar fortemente essas propriedades. Aparentemente, houve uma boa dispersão e interação da argila organofílica com a matriz de PA6, favorecendo ao aumento da rigidez do compósito. O teor de 3\% parece ser suficiente para a melhoria das propriedades.

A Figura 7 apresenta as fotomicrografias do PA6 puro e dos compósitos de PA6/argila sem tratamento e tratada com o sal brometo. Na Figura 7(a), observa-se a superfície de fratura da PA6 mostrando a direção da deformação. Na Figura 7 (b) - PA6/AST (3\%), observam-se vazios na morfologia, o que indica que provavelmente aglomerados de argila foram arrancados da matriz durante a solicitação por tração, com- 


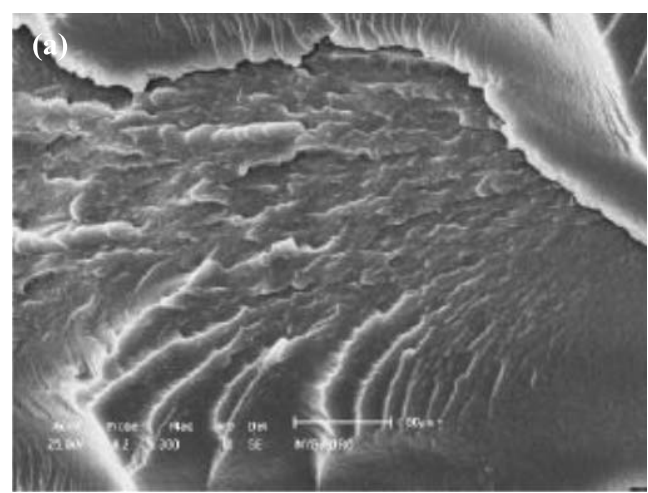

(300 X)

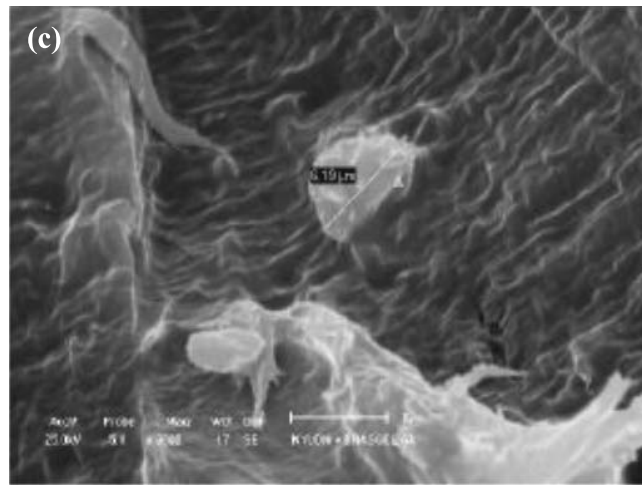

(300 X)

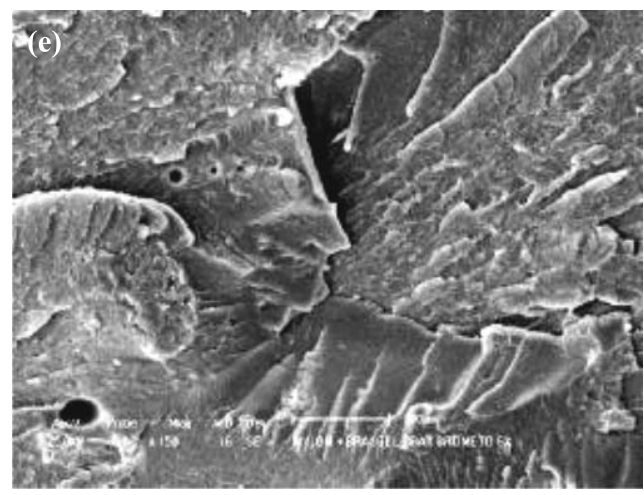

(300 X)

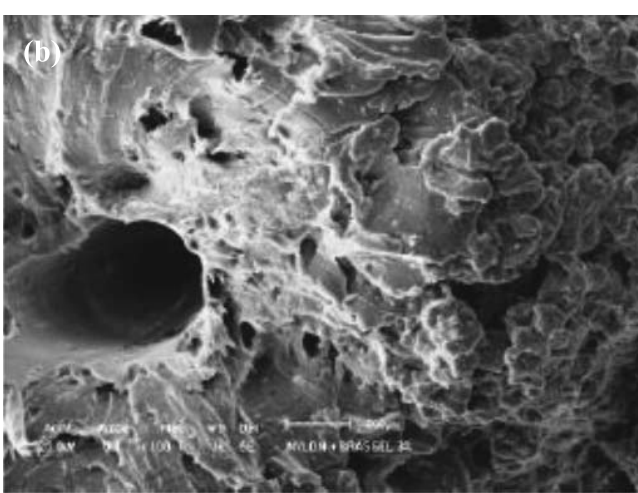

(300 X)

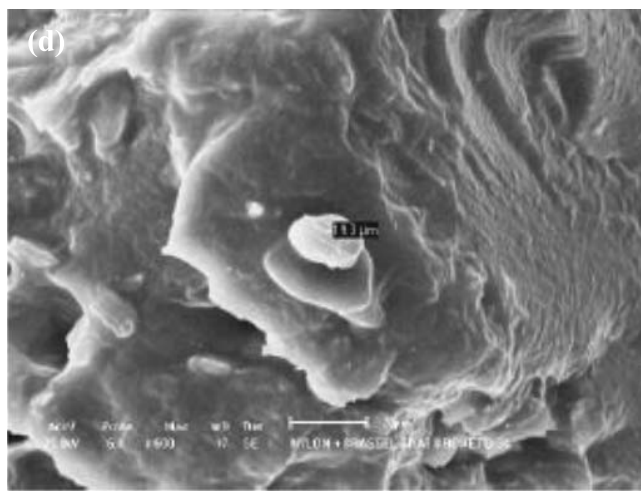

(300 X)

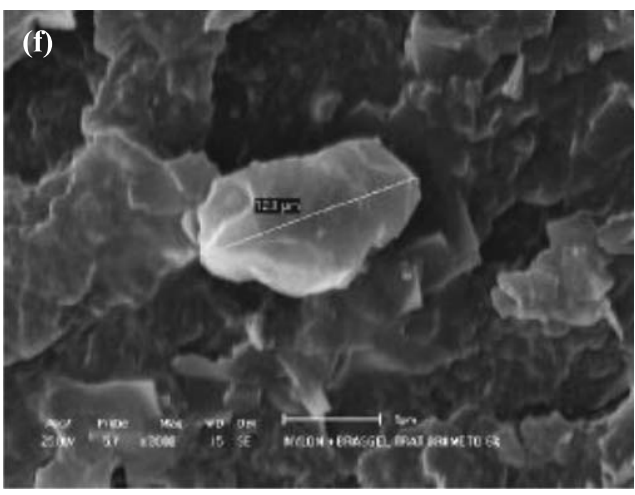

(300 X)

Figura 7 - Fotomicrografias de MEV para amostras de PA6: (a) PA6 puro; (b) PA6 /argila sem tratamento (3\%); (c) PA6/argila sem tratamento (6\%); (d) PA6 /argila com tratamento (3\%); (e) e (f) PA6/argila com tratamento (6\%).

prometendo dessa forma as propriedades mecânicas em relação à PA6 com argila tratada, como indicado na Tabela 4. A região ao redor desse aglomerado aparenta ser deformação plástica. Na Figura 7(c) - PA6/AST (6\%), observa-se a presença de argila e de acordo com análise por EDX, esta contém os elementos $\mathrm{C}, \mathrm{O}, \mathrm{Al}, \mathrm{Si}$ e Fe. A dimensão dessa fase dispersa (aglomerado) fica em torno de 6,19 $\mu \mathrm{m}$. Nas Figuras 7 (d) a (f) - PA6/ACT (3\%) e PA6/ACT (6\%), respectivamente, observam-se partículas dispersas, onde a dimensão destas é de 19,3 $\mu \mathrm{m}$ (Fig. 7d) a 12,0 $\mu \mathrm{m}$ (Fig. 7f). A Figura 7 (e) mostra pequenos vazios que não dá para dizer se estes são devido a bolhas presentes na matriz ou falta de adesão da argila com o nylon. Das fotomicrografias observadas, aparentemente pode-se dizer que houve adesão da matriz com a argila tratada, devido à presença do sal brometo o que é revelado por meio das propriedades mecânicas. Entretanto, não dá para mencionar se houve ou não intercalação e boa dispersão, ou seja, a formação de um nanocompósito propriamente dita.

\section{Conclusões}

Argilas organofílicas foram obtidas a partir de argilas bentoníticas sintetizadas com quatro tipos de sais quaternários de amônio. Os resultados mostraram a presença dos grupos característicos dos sais na argila e a intercalação destes entre as camadas da argila, a partir das técnicas de FTIR e DRX, respectivamente. Os resultados das propriedades mecânicas 
das misturas mostraram um aumento na rigidez destas em relação aos polímeros puros.

\section{Agradecimentos}

Os autores agradecem à Braskem/SA pelo fornecimento do PE, à Rhodia pelo fornecimento do Nylon6, à Bentonit União Nordeste pelo fornecimento da argila, a Clariant pela doação dos sais, à FAPESQ (Fundação de Apoio a Pesquisa do Estado da Paraíba) e à RENAMI (Rede de Nanotecnologia Molecular e de Interfaces) pelo apoio financeiro e ao Prof. Severino Jackson Guedes de Lima do CT/UFPB/João Pessoa pelas análises de DR-X.

\section{Referências Bibliográficas}

1. Souza Santos, P. - "Tecnologia de Argilas, Aplicada às Argilas Brasileiras”, Edgard Blücher, São Paulo (1975).

2. Zilg, C.; Diestsche, F.; Engelhardt, T. \& Miilhaust, R. Plástico Industrial, p. 64 (2000).

3. Ramos, R. R. - "Estudo de Algumas Propriedades Reológicas e Teores de Carbonato e Bicarbonato Após Cura em Câmara Úmida e Autoclave de Três Argilas Esmectíticas Tratadas com Carbonato de Sódio da Localidade de Bravo, Distrito de Boa Vista, Município de Campina Grande, Paraíba". Dissertação de Mestrado, Universidade Federal da Paraíba, Brasil, (1985).

4. Souza Santos, P. - "Ciência e Tecnologia de Argilas", Edgard Blücher, São Paulo (1989).

5. Souza Santos, P. - “Ciência e Tecnologia de Argilas", Edgard Blücher, São Paulo (1992).

6. Gomes, C. F. - "Argilas: o que são e para que servem", Fundação Calouste Gulbenkian, Lisboa, (1988).

7. Valenzuela-Díaz, F. R. - “Obtenção de Argilas Organofílicas Partindo-se de Argila Esmectítica e do Sal Quaternário de Amônio ARQUAD 2HT-75", in: Anais do 43
Congresso Brasileiro de Cerâmica, p. 43201, Florianópolis - SC (1999).

8. Valenzuela-Díaz, F. R. - "Preparação ao Nível de Laboratório de Algumas Argilas Esmectíticas Organofílicas", Tese de Doutorado, Escola Politécnica da Universidade de São Paulo, Brasil (1994).

9. Valenzuela-Díaz, F. R. - Key Eng. Mat., 189-191, p. 203 (2001)

10. Araújo, E. M.; Mélo, T. J. A.; Santana, L. N. L.; Neves, G. A.; Ferreira, H. C.; Lira, H. L.; Carvalho, L. H.; Ávila Jr., M. M.; Pontes, M. K. G. \& Araújo, I. S. - Mat. Sci. and Eng. B, 112, p. 175 (2004).

11. Vieira José, C. L.; Pinto, C. A.; Valenzuela-Díaz, F. R. \& Buchler, P. M. - "Sintetização de Argilas Organofílicas Visando seu Uso no Controle Ambiental de Resíduos de Fenol", in: Anais do $46^{\circ}$ Congresso Brasileiro de Cerâmica, p. 1685, São Paulo - SP (2002).

12. Araújo, E. M.; Mélo, T. J. A.; Santana, L. N. L.; Barbosa, R.; Oliveira, A. D.; Ferreira, H. S.; Araújo, H. L. \& Ávvila Jr., M. M. - "Sinterização e Caracterização de Argilas Organofílicas a partir de Diferentes Sais Quaternários de Amônio visando sua Utilização em Nanocompósitos", in: Anais do $48^{\circ}$ Congresso Brasileiro de Cerâmica, p. 1, Curitiba - PR (2004).

13. Abreu, S. F. - "Recursos Minerais do Brasil", Edgard Blücher, São Paulo (1973).

14. Lira Filho, D. P. - "Perfil Analítico da Bentonita. Ministério das Minas e energia, Departamento Nacional da Produção Mineral (DNPM), Boletim, 4, p. 33 (1973).

15. Zanetti, M. \& Costa, L. - Polymer, 45, p. 4367 (2004).

16. Gong, F. L.; Zhao, C. G. Feng, M.; Qin, H. L. \& Yang, M. S. - J. Mat. Sci., 39, p. 293 (2004).

Enviado: 07/03/05

Reenviado: 19/08/05

Aprovado: 17/10/05 